Article

\title{
Self-Agglomeration in Fluidised Beds after Spray Drying
}

\author{
John J. Fitzpatrick ${ }^{1, *}$, Shaozong $\mathrm{Wu}^{1,2}{ }^{1}$ Kevin Cronin ${ }^{1}$ and Song Miao ${ }^{2, *}$ \\ 1 Process \& Chemical Engineering, School of Engineering, University College Cork, T12 K8AF Cork, Ireland; \\ Shaozong.Wu@teagasc.ie (S.W.); k.cronin@ucc.ie (K.C.) \\ 2 Teagasc Food Research Centre, Moorepark, Fermoy, Co., P61 C996 Cork, Ireland \\ * Correspondence: j.fitzpatrick@ucc.ie (J.J.F.); Song.Miao@teagasc.ie (S.M.); \\ Tel.: +353-21-4903089 (J.J.F.); +353-25-42468 (S.M.)
}

Received: 14 April 2020; Accepted: 3 June 2020; Published: 5 June 2020

check for updates

\begin{abstract}
Many powders are produced in spray-drying processes from liquid concentrates. Self-agglomeration can be performed in a fluidised bed where the spray-dried powder is agglomerated using the liquid concentrate as the binder material. This has advantages over traditional wet agglomeration in fluid beds using liquid binders (such as water or sugar solutions). These include thermal energy savings and no additional non-aqueous binder components added. The work presented has two parts. The first part is experimental, which investigated the self-agglomeration of whey protein isolate (WPI) powder as a case-study. It showed that satisfactory agglomeration was achieved with a great improvement in the wettability of the powder. The second part of the work performed thermal energy analysis to estimate the energy saving potential of self-agglomeration, and how this is influenced by binder to powder ratio and binder solids concentration. For the WPI case-study, the analysis showed there is potential for a $19 \%$ saving in thermal energy requirement for self-agglomeration in comparison to traditional agglomeration using a water binder.
\end{abstract}

Keywords: self-agglomeration; fluid-bed agglomeration; spray drying; thermal energy; WPI powder

\section{Introduction}

Wet agglomeration may be applied for improving the functionality of powders, such as better wettability and flowability, and reducing dustiness problems [1-3]. It is commonly carried out in fluidised beds and mixer granulators, where a binder is sprayed onto the primary powder particles to form liquid bridges between particles to produce wet granules, which are subsequently dried to form solid bridges, resulting in stronger agglomerates [4,5]. Ji et al. [6] investigated the effect of fluid-bed wet agglomeration on the wettability of high-protein dairy powders. They showed that it greatly improved the wettability of milk protein isolate (MPI) and whey protein isolate (WPI) powders. Specifically, Ji et al. [7] investigated the effect of water, lactose and sucrose solution binders on fluid-bed wet agglomeration of MPI powder and showed similar improvements in wettability with each binder. Ji et al. [8] also showed that fluid-bed wet agglomeration improved the flowability of MPI powder, as measured using shear cell techniques.

The disadvantages of wet agglomeration are that it uses a binder which requires energy to vaporise water during the drying step. Furthermore, any non-aqueous components in the binder solution, such as sugars, represent an additional component added to the agglomerated powder which may not be desirable. An alternative approach, termed here as "self-agglomeration", has the potential to overcome some of these disadvantages, and is applied in this paper to the agglomeration of WPI powder. Self-agglomeration is applied in the context of the drying of a liquid concentrate, such as WPI concentrate in spray drying, to produce WPI powder. Self-agglomeration is a wet agglomeration 
process that could be performed in, for example, a fluidised bed. The key point is that the binder liquid used is the original concentrate. For example, WPI concentrate would be used as the binder to agglomerate spray-dried WPI powder in an external fluidised bed, as illustrated in Figure 1a. Alternatively, the self-agglomeration could also be undertaken in a fluid bed integrated into the bottom of the spray dryer, as illustrated in Figure $1 \mathrm{~b}$. The focus of this paper is on self-agglomeration in a fluid bed and to compare it to traditional wet agglomeration in a fluid bed using a liquid binder. Self-agglomeration has the following two advantages:

(i) There is no additional binder water being vaporised, because the binder is the concentrate. It just means that some of the water in the concentrate is vaporised during agglomeration rather than during spray drying. This has the potential to reduce the thermal energy requirement associated with the overall spray drying and wet agglomeration process. However, in some cases, it may prove difficult to agglomerate due to high solids concentration in the concentrate. Consequently, some binder dilution with water may be required, and this will reduce the potential energy saving associated with self-agglomeration.

(ii) There is no additional non-aqueous binder components added, as the composition of the solid bridges in the agglomerates is the same as the primary powder particles, e.g., WPI.
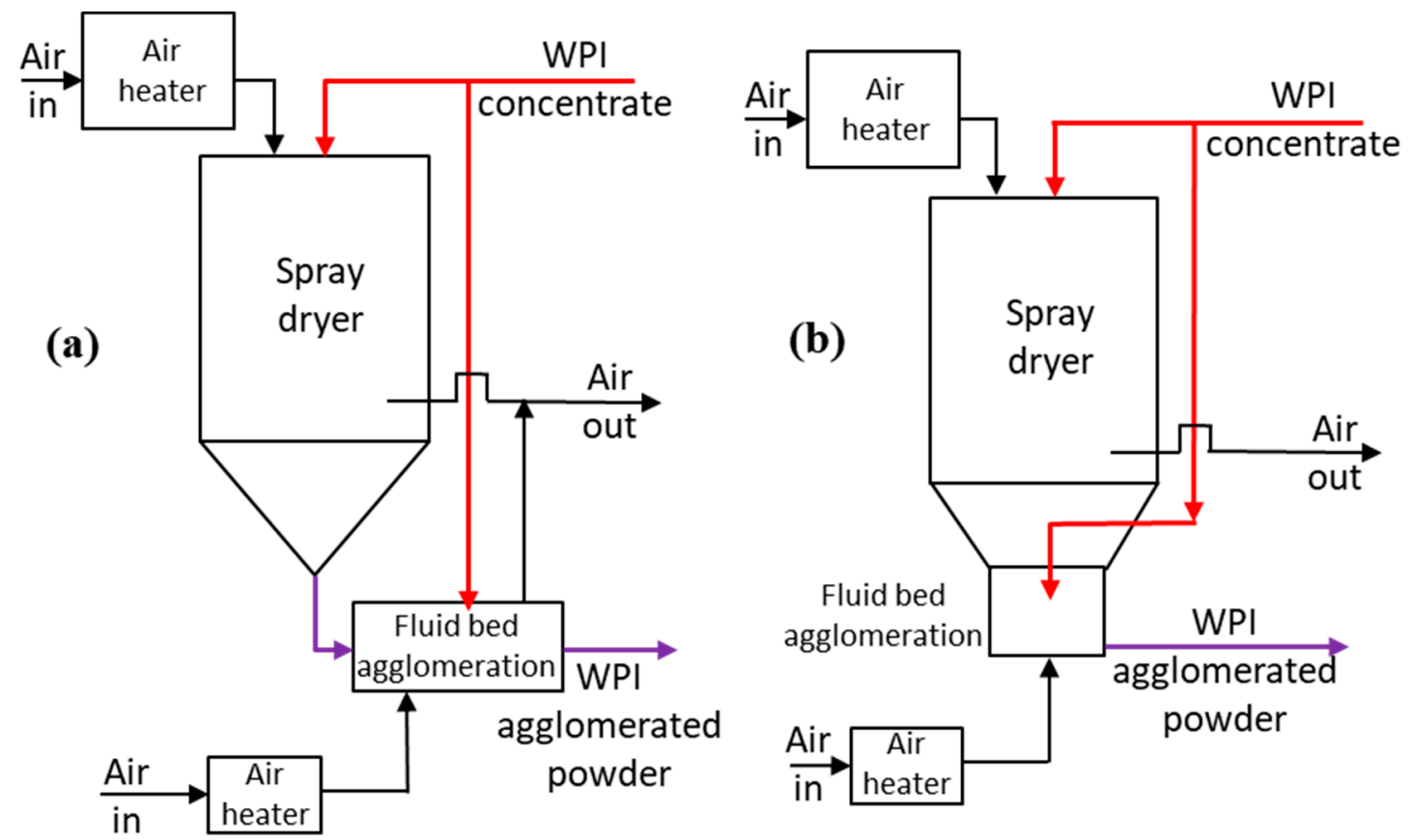

Figure 1. Schematic diagram of the application of self-agglomeration in the production of whey protein isolate (WPI) agglomerated powder (a) agglomeration in external fluid bed, (b) agglomeration in integrated fluid bed.

Many food powders, such as dairy powders and infant milk formula powders, are manufactured by the drying of liquid concentrates in spray dryers. The spray dryers usually have an integrated fluid bed and/or external fluid bed where final drying and cooling is performed. This improves the overall energy efficiency by increasing the temperature difference between the supply air and the outgoing air [9].

Another commonly used approach to self-agglomeration is where fines, separated from the spray-dryer exhaust air, are fed back into the concentrate spray zone in the top of the spray-drying chamber [9]. Chever et al. [10] conducted pilot-scale work on a number of different approaches to agglomerating whole milk powder within the spray-drying chamber. This included the feeding of fines back into the spray-dryer concentrate spray zone, and wet agglomeration in an integrated fluid 
bed using water as a binder. They showed that better wettability was obtained by wet agglomeration in the integrated fluid bed with a wetting time of $14 \mathrm{~s}$ in comparison to a wetting time of $47 \mathrm{~s}$ for the agglomerates produced from feeding fines into the concentrate spray zone. This highlights that there may be advantages to self-agglomeration in fluid beds in terms of superior functional properties of the agglomerated powders.

This paper focuses on self-agglomeration in a fluid bed, and examines it from two distinct but inter-related perspectives. Firstly, it experimentally investigates the self-agglomeration of spray-dried WPI powder and how the amount of binder and binder solids concentration affect the self-agglomeration of WPI powder, in terms of agglomerate physical properties and powder wettability (considering that WPI powder is a poor wetting powder). The experimentation is presented in Section 2.1 and the results from it in Section 3.1. Secondly, thermal energy modelling is presented and applied to estimate the potential thermal energy saving of self-agglomeration in comparison to traditional wet agglomeration (using water as a binder), and how this is influenced by key selected parameters. The mathematical modelling is presented in Section 2.2 and the results from it in Section 3.2.

\section{Materials and Methods}

\subsection{Experimentation}

\subsubsection{Materials}

WPI powder was purchased from Carbery Food Ingredients (Ballineen, Ireland). The powder was composed of protein $(>90 \%)$, fat $(<1 \%)$, ash $(<4 \%)$ and lactose $(<2 \%)$. Ultra-distilled water was prepared by a Milli-Q apparatus (Millipore Corp.) to prepare solutions in this study.

\subsubsection{Preparation of Agglomerated WPI Powder}

The effect of percentage of WPI in the WPI binder solution is an important parameter in self-agglomeration. A set of experiments were performed to investigate this. A number of WPI binder solutions, with different $\%$ solids concentrations, were prepared by adding an appropriate mass of WPI powder into $50 \mathrm{~mL}$ of distilled water. The solutions were stirred for $3 \mathrm{~h}$ to allow full rehydration prior to fluid-bed agglomeration. The percentage of WPI in the WPI binder solutions was set at $0 \%$ (distilled water), $10 \%, 20 \%$ and $30 \%(w / v)$ WPI solutions. The $0 \%$ (distilled water) is representative of a binder solution used in traditional wet agglomeration using water as a binder.

A quantity of $100 \mathrm{~g}$ of WPI powder was used in the fluid bed (VFC-Lab Micro flo-coater (1200 mL), Vector Corporation, Iowa, USA). The mode of spraying was top-spray and the air pressure in the spray nozzle was 1 bar. The air flowrate was carried out at $60 \mathrm{~L} \mathrm{~min}^{-1}$ until the end of binder addition, and was then increased to $90 \mathrm{~L} \mathrm{~min}^{-1}$ for drying. The air temperature during both agglomeration and drying was $50^{\circ} \mathrm{C}$, and the drying time was $20 \mathrm{~min}$. The binder solutions were sprayed at a flowrate of $2 \mathrm{~mL} \mathrm{~min}{ }^{-1}$. The binder solutions were kept stirred at a speed of $450 \mathrm{rpm}$ and a temperature of $50^{\circ} \mathrm{C}$ prior to spraying.

\subsubsection{Powder Physical Properties}

The particle size of the original WPI powder and agglomerated powders was measured using a Mastersizer 3000 (Malvern Instruments Ltd., Worcestershire, UK) under 0.4 bar air pressure, from which the median particle size $\left(D_{50}\right)$ was obtained. Measurements were conducted in triplicate.

Poured bulk density and tapped bulk density of the WPI powders were measured using a graduated cylinder and a tapping machine (Funke Gerber, Berlin, Germany). The volume occupied by a given mass of powder, before and after 500 taps, was measured to calculate the bulk densities. Apparent density of WPI powder samples was measured by a pycnometer (AccuPyc II 1340, Micromeritics Instrument 
Corporation, Georgia, USA). These measurements were performed in triplicate. The porosity $(\epsilon)$ was calculated from Equation (1).

$$
\epsilon=100\left(\frac{\rho_{A}-\rho_{T}}{\rho_{A}}\right)
$$

where $\rho_{T}$ and $\rho_{A}$ are the tapped bulk density and apparent density, respectively.

\subsubsection{Powder Wettability}

An Optical tensiometer (Attension Theta, Biolin Scientific Ltd., Espoo, Finland) was utilised to perform the measurement of wettability of the different WPI powders using the sessile drop technique [6]. A $5 \mu \mathrm{L}$ deionized water droplet was dropped onto the WPI powder bed, and the contact angle between the powder bed and droplet was recorded in real time. The experiments were conducted in triplicate.

\subsubsection{Statistics}

One-way analysis of variance (ANOVA) was applied to compare means of data by SPSS software (IBM SPSS Statistics version 24) and significant difference at $p<0.05$ was run by Duncan test.

\subsection{Thermal Energy Modelling during Spray Drying and Fluid-Bed Agglomeration}

The following approximate thermal energy analysis is developed for the system presented in Figure 1a, to provide an insight into thermal energy requirements and the thermal energy savings associated with self-agglomeration in comparison to traditional agglomeration (using a water binder). The analysis is undertaken for a fixed agglomerated powder production mass flowrate $\left(P_{r}\right)$. The binder to powder ratio is expressed as the ratio of mass of water in the binder to the mass of powder entering the fluid bed $\left(R_{w p}\right)$.

The ratio $\left(R_{w p}\right)$ is expressed as in Equation (2).

$$
R_{w p}=\frac{M_{w b}}{M_{p s}}
$$

where $M_{w b}$ is the mass flowrate of water within the binder solution and $M_{p s}$ is the mass flowrate of powder leaving the spray dryer and entering the fluid bed.

The binder mass flowrate $\left(M_{b}\right)$ is evaluated using Equation (3), which is derived from the fact that the binder is made up of solids and water.

$$
M_{b}=M_{b} X_{b}+M_{w b}
$$

where $X_{b}$ is the binder solids concentration.

A solids mass balance on the control volume containing spray drying and fluid-bed agglomeration is presented in Equation (4).

$$
M_{c} X_{c}+M_{b} X_{b}=P_{r} X_{p}
$$

where $M_{\mathcal{c}}$ is the concentrate mass flowrate to the spray dryer having a solids concentration $\left(X_{\mathcal{c}}\right)$, and $X_{p}$ is the solids concentration of the final agglomerated powder.

A solids mass balance on the spray dryer is presented in Equation (5).

$$
M_{c} X_{c}=M_{p s} X_{p s}
$$

where $X_{p s}$ is the solids concentration of the dried powder leaving the spray dryer. and $M_{c}$.

Equations (2) to (5) are an implicit set of equations which are used to evaluate $M_{b}, M_{w b}, M_{p s}$ 
The rate of water vaporisation in the spray $\operatorname{dryer}\left(M_{w s}\right)$ is evaluated from a total mass balance on the spray dryer (Equation (6)).

$$
M_{w s}=M_{c}-M_{p s}
$$

The mass flowrate of air required in the spray dryer $\left(M_{a s}\right)$ is estimated from the thermal energy balance (Equation (7)) applied to the spray dryer.

$$
M_{a s} C_{p a}\left(T_{a i}-T_{a e}\right)=M_{w s} \lambda_{v}
$$

where $M_{a s}$ is the mass flowrate of air entering the spray dryer; $C_{p a}$ is the specific heat of air $\left(=1 \mathrm{~kJ} \mathrm{~kg}^{-1}{ }^{\circ} \mathrm{C}^{-1}\right) ; \lambda_{v}$ is the latent of vaporisation of water $\left(=2382 \mathrm{~kJ} \mathrm{~kg}^{-1}\right.$ at a vaporisation temperature of $\left.50^{\circ} \mathrm{C}\right) ; T_{a i}\left(180^{\circ} \mathrm{C}\right)$ and $T_{a e}\left(70^{\circ} \mathrm{C}\right)$ are spray-dryer inlet and outlet air temperatures, respectively. These temperatures are representative of temperatures used in milk powder production [9].

To simplify the comparative energy analysis, Equation (7) assumes that the energy lost by the drying air (in the drying chamber) is used to vaporise water only and that other energy terms are small in comparison. It is assumed that powder leaves the drying chamber at $50{ }^{\circ} \mathrm{C}$ (i.e., $20^{\circ} \mathrm{C}$ below outlet air temperature) and the concentrate enters at the same temperature. It is also assumed that heat losses from the drying chamber are relatively small.

The spray-dryer thermal energy $\left(E_{t h} S\right)$ requirement is the thermal energy required to heat the dryer air from ambient temperature $\left(T_{a m b}=15^{\circ} \mathrm{C}\right)$ to the dryer inlet air temperature, and is evaluated in Equation (8).

$$
E_{t h \_} S=M_{a s} C_{p a}\left(T_{a i}-T_{a m b}\right)
$$

The rate of water vaporisation in the fluid bed $\left(M_{w f}\right)$ is evaluated in Equation (9) by performing a water mass balance on the fluid bed.

$$
M_{w f}=M_{w b}+M_{p s}\left(1-X_{p s}\right)-M_{p}\left(1-X_{p}\right)
$$

The mass flowrate of air to fluid-bed agglomeration $\left(M_{a f}\right)$ is estimated from the thermal energy balance in Equation (10). This assumes that the energy lost by the drying air is used to vaporise water only and that other energy terms are small in comparison. It is assumed that the temperature of the powder leaving the fluid is the same as that entering, i.e., $50{ }^{\circ} \mathrm{C}$, and the binder is also at this temperature.

$$
M_{a f} C_{p a}\left(T_{a i_{-} f}-T_{a e_{-} f}\right)=M_{w f} \lambda_{v}
$$

where $T_{a i_{-} f}\left(70^{\circ} \mathrm{C}\right)$ and $T_{a e_{-} f}\left(50^{\circ} \mathrm{C}\right)$ are fluid-bed inlet and outlet air temperatures, respectively, and are representative of temperatures used in milk powder production [9].

The fluid-bed thermal energy $\left(E_{t h \_} s\right)$ requirement is the thermal energy required to heat the air from ambient temperature $\left(T_{a m b}=15^{\circ} \mathrm{C}\right)$ to the fluid-bed inlet air temperature, and is evaluated in Equation (11).

$$
E_{t h \_}=M_{a f} C_{p a}\left(T_{a i_{-} f}-T_{a m b}\right)
$$

Percentage thermal energy saving associated with self-agglomeration in comparison to traditional wet agglomeration is given in Equation (12).

$$
\% \text { Energy Saving }=100\left(\frac{E_{\text {th_trad }}-E_{t h \_s e l f}}{E_{\text {th_trad }}}\right)
$$

where $E_{\text {th_trad }}$ and $E_{\text {th_self }}$ are the total thermal energies (spray drying + fluid bed) associated with spray dry/traditional wet agglomeration and spray dry/self-agglomeration, respectively. 


\section{Results and Discussion}

\subsection{Effect of Binder to Powder Ratio and Binder Solids Concentration on Agglomeration of WPI}

The binder to powder ratio $\left(R_{w p}\right)$ and binder solids concentration $\left(X_{b}\right)$ are important parameters that affect both powder agglomeration and thermal energy requirement. These parameters may vary from powder to powder. Laboratory- or pilot-scale testing is required to evaluate the effect of these parameters on the agglomeration and the consequential physical and functional properties of the agglomerates. This section focusses on the influence of $R_{w p}$ and $X_{b}$ on the physical and functional properties of WPI agglomerates.

In previous experimental work conducted by Ji et al. [6], laboratory-scale fluid-bed agglomeration of a number of high-protein milk powders was performed, including WPI. The binder used was a $15 \%$ lactose solution. As the different milk powders had different physical and chemical properties and fluidisation behaviours, the ratio of binder to powder required to satisfactorily agglomerate the powders varied from 20 to $50 \mathrm{~g}$ of water (in the binder solution) per $100 \mathrm{~g}$ of powder. For WPI powder, this was around 40 to $50 \mathrm{~g}$ of water per $100 \mathrm{~g}$ of powder. Considering this, WPI binder solutions were prepared containing $50 \mathrm{~g}$ of water per $100 \mathrm{~g}$ of powder (i.e., $R_{w p}=0.5$ ).

A set of experiments was performed to investigate the effect of binder solids concentration $\left(X_{b}\right)$. It has been reported that WPI can be concentrated up to about 35-38\% solids concentration by membrane processing prior to spray drying [11]. Consequently, this should act as an upper limit to the percentage of WPI in the binders used in this study. However, it proved to be very difficult trying to rehydrate WPI powder to $35 \%$ solids concentration in the laboratory. Consequently, this was limited to $30 \%(w / v)$ solids concentration, and consequently, the binder solutions were prepared with different \% WPI in WPI binder solution ( $\%$ to 30\% WPI), as described in Section 2.1.2 Agglomerations were performed to investigate its effect on the physical properties and wettability (as an important functional property) of the WPI agglomerates. The results of this investigation are presented in the following sections.

\subsubsection{Powder Physical Properties}

The effect of \% WPI in WPI binder solution on powder particle size distribution (PSD) is illustrated in Figure 2, and the corresponding median sizes $\left(\mathrm{D}_{50}\right)$ are presented in Table 1 . These data show that significant agglomeration was achieved, with the $\mathrm{D}_{50}$ values of the agglomerated powders being over two times greater than that of the original WPI powder. The particle sizes for the $10 \%$ WPI was very similar to the $0 \%$ (distilled water), with $\mathrm{D}_{50}$ values of about $138 \mu \mathrm{m}$. There was a significant increase in particle size for the $20 \% \mathrm{WPI}$, having a $\mathrm{D}_{50}$ value of $154 \mu \mathrm{m}$. Increasing the $\% \mathrm{WPI}$ to $30 \%$ caused a reduction in $\mathrm{D}_{50}$ to $122 \mu \mathrm{m}$.

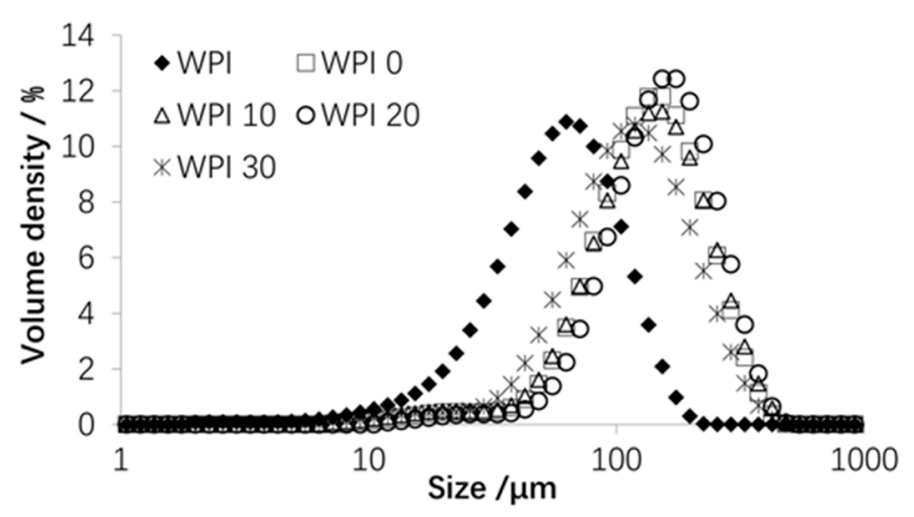

Figure 2. Particle size distributions of original and agglomerated WPI powders. 
Table 1. Particle size, densities and porosity of the original WPI powder (WPI) and the agglomerated powders with different \% WPI in the WPI binder solution ( $0 \%$ WPI to $30 \%$ WPI).

\begin{tabular}{|c|c|c|c|c|c|}
\hline & WPI & $0 \%$ WPI & $10 \%$ WPI & $20 \% \mathrm{WPI}$ & $30 \%$ WPI \\
\hline Median Size $(\mu \mathrm{m})$ & $58.5 \pm 0.9^{a}$ & $137.7 \pm 2.9^{c}$ & $138.7 \pm 1.5^{\mathrm{c}}$ & $154.3 \pm 0.6^{d}$ & $122.3 \pm 1.5^{b}$ \\
\hline Poured Density (g/L) & $367 \pm 10^{d}$ & $247 \pm 3^{c}$ & $246 \pm 0^{c}$ & $201 \pm 11^{\mathrm{a}}$ & $224 \pm 5^{b}$ \\
\hline Tapped Density (g/L) & $459 \pm 2^{d}$ & $302 \pm 7^{b}$ & $316 \pm 6^{c}$ & $271 \pm 4^{\mathrm{a}}$ & $316 \pm 4^{c}$ \\
\hline Apparent Density (g/L) & $974 \pm 13^{a}$ & $959 \pm 1^{a}$ & $964 \pm 2^{a}$ & $974 \pm 1^{\mathrm{a}}$ & $967 \pm 2^{a}$ \\
\hline Porosity $(\%)$ & 52.9 & 68.5 & 67.2 & 72.2 & 67.3 \\
\hline
\end{tabular}

Different superscript letters indicate significant differences between values in a row $(p<0.05)$.

The effect of \% WPI in WPI binder solution on powder densities and porosity is presented in Table 1. As expected, agglomeration resulted in a decrease in both poured and tapped bulk densities. The bulk densities values for the $0 \%, 10 \%$ and $30 \%$ WPI were somewhat similar, with tapped values between 302 and $316 \mathrm{~g} \mathrm{~L}^{-1}$, while the values for the $20 \%$ WPI were significantly lower, with a tapped value of $271 \mathrm{~g} \mathrm{~L}^{-1}$. These trends are somewhat similar to the particle size data where the $20 \%$ WPI was much larger than the others. Consequently, it is possible that the lower density of the $20 \%$ WPI may be related to its larger particle size.

The apparent densities of the all the agglomerates and the original WPI powder were similar at around 960 to $975 \mathrm{~g} \mathrm{~L}^{-1}$. This is not surprising as the pycnometer gas is easily able to penetrate into the void spaces between the WPI primary particles.

\subsubsection{Wettability}

The wettability of the original WPI powder is very poor, as illustrated in Figure 3, with the contact angle decreasing slowly from around $130^{\circ}$ to $120^{\circ}$ after $10 \mathrm{~s}$. Figure 3 shows a great improvement in wettability was achieved by agglomeration with the distilled water and all the WPI binder solutions, where contacts angles decreased rapidly to zero in less than $10 \mathrm{~s}$. This is most likely due to the water droplet being more easily able to penetrate into the larger void spaces between the agglomerate particles [6]. Overall, these results showed that self-agglomeration using at least 30\% WPI binder solids concentration can be applied to produce agglomerates with greatly enhanced wettability.
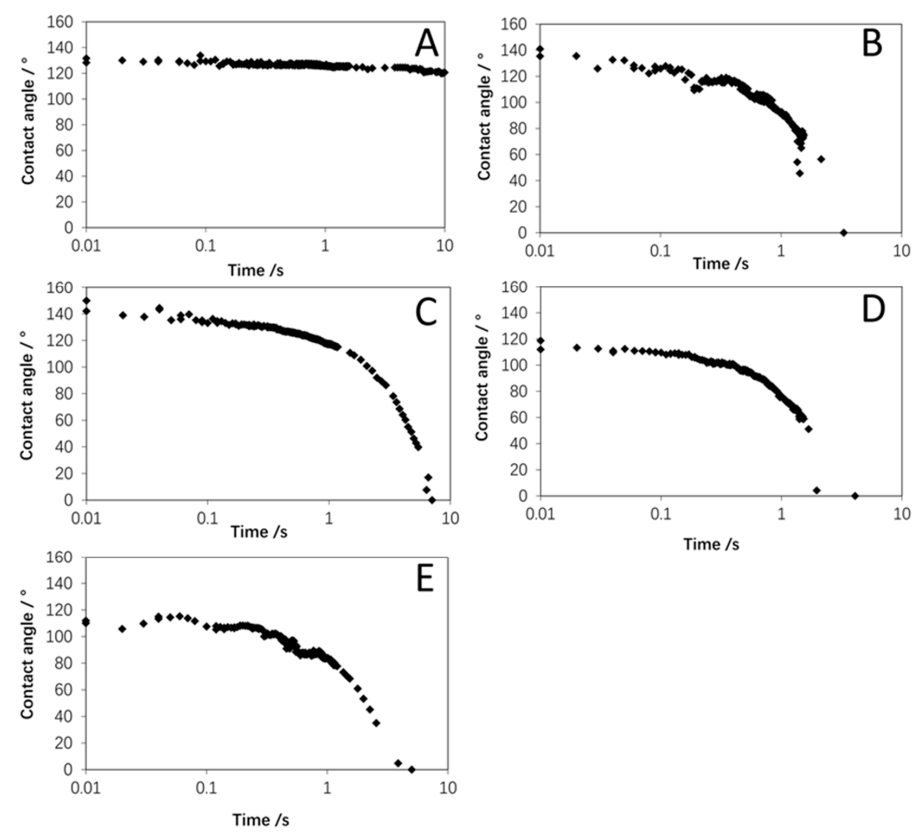

Figure 3. Contact angle data for original WPI powder (A), and agglomerated powders: (B) 0\% WPI; (C) 10\% WPI; (D) 20\% WPI; (E) 30\% WPI. 


\subsection{Analysis of Thermal Energy Savings Associated with Self-Agglomeration of Spray-Dried Powder in Comparison to Traditional Wet Agglomeration}

Drying is a highly energy-intensive process, and this is mainly due to the need for supplying the latent heat of vaporisation to vaporise off water or other solvents [12]. Drying is extensively used throughout the process industries, thus reducing its energy requirement is important in terms of reducing both process costs and environmental impacts. Energy analysis and modelling can contribute to quantitatively assessing energy reductions associated with different approaches to saving energy [12-16].

As highlighted earlier, self-agglomeration has the potential to reduce the thermal energy requirement associated with the overall spray-drying/wet agglomeration process when compared to traditional wet agglomeration. In traditional fluid-bed agglomeration, additional water is being added in the binder and energy is required to vaporise it. In self-agglomeration, no additional water is being added (or a greatly reduced amount is added) because the binder is sourced from the concentrate. This means that some of the water in the concentrate is vaporised during agglomeration rather than during spray drying.

The analysis was undertaken for an agglomerated powder production rate of $P_{r}=1 \mathrm{~kg} \mathrm{~s}^{-1}$. For the sake of energy comparison, it is assumed that the value of $R_{w p}$ is the same for self-agglomeration and traditional agglomeration (using a water binder). This means that the same mass of water is being added in the binder per $\mathrm{kg}$ of powder entering the fluid bed for both self-agglomeration and traditional wet agglomeration.

Important parameters that influence the thermal energy analysis and the thermal energy savings associated with self-agglomeration are:

1. Mass of binder to powder ratio in both wet agglomerations.

2. Solids concentration in the binder applied during self-agglomeration $\left(X_{b}\right)$.

3. Solids concentration in the concentrate $\left(X_{c}\right)$ to the spray dryer [this will vary depending on the powder produced].

The next section applies the thermal energy analysis to the WPI powder case-study. The following three sections investigate the influence on the thermal energy analysis of the three important parameters, highlighted above.

\subsubsection{Comparison of Thermal Energy Requirement for Self-Agglomeration and Traditional Wet Agglomeration of WPI Powder}

The modelling presented in Section 2.2, of the system presented in Figure 1a, is firstly applied to the specific case of WPI powder, where a comparison is undertaken of the thermal energy requirement for self-agglomeration and traditional wet agglomeration (using a water binder). In the specific case, the $R_{w p}$ ratio is assigned a value of 0.5 and is the same for both agglomerations. The solids concentration in the concentrate entering the spray dryer is $36 \%$ and the powder exiting the dryer is at $93 \%$ solids [9]. The binder solids concentration is 30\% for self-agglomeration and the agglomerated powder leaves the fluid bed at $97 \%$ solids [9]. This case approximates the self-agglomeration of WPI. The comparison of the thermal energy requirements (along with relevant flowrates) is presented in Table 2.

The concentrate flowrate requirement to the spray dryer is around $19 \%$ lower for self-agglomeration because some of the concentrate is used as binder. This results in a consequential 19\% reduction in both water vaporisation and powder leaving the spray dryer, which results in a $19 \%$ reduction in thermal energy requirement in the spray dryer.

The binder flowrate for self-agglomeration is $16 \%$ greater than for traditional agglomeration because it contains $30 \%$ solids. Even though the ratio $R_{w p}$ is the same for both, the water vaporisation is lower for self-agglomeration in the fluid bed because less powder is produced in the spray dryer. The lower powder flowrate to the fluid bed results in a lower binder water flowrate $\left(M_{w b}\right)$, which results in nearly a $20 \%$ reduction in fluid-bed thermal energy requirement to vaporise the binder water and 
reduce the water content of the powder. Overall, for this specific case considering both spray drying and fluid-bed agglomeration, there is a $19.1 \%$ saving in thermal energy requirement for self-agglomeration in comparison to traditional wet agglomeration using a water binder.

Table 2. Comparison of thermal energy requirement (and relevant flowrates) for self-agglomeration (with binder solids concentration $X_{b}=30 \%$ ) and traditional wet agglomeration (using a water binder). This is for the case of $R_{w p}$ ratio $=0.5$ for both agglomerations. The solids concentration entering the spray-dryer is $36 \%$. [flowrates are in $\mathrm{kg} \mathrm{s}^{-1}$ and thermal energy requirement is in $\mathrm{kW}$ ].

\begin{tabular}{cccc}
\hline & Agglom with Water & Self-Agglom $\left(\boldsymbol{X}_{\boldsymbol{b}}=\mathbf{3 0} \mathbf{0}\right)$ & \% Change \\
\hline Spray drying & & & \\
Concentrate flowrate $\left(M_{\mathcal{c}}\right)$ & 2.69 & 2.19 & -18.7 \\
Rate of water vaporisation $\left(M_{w s}\right)$ & 1.65 & 1.34 & -18.7 \\
$\quad$ Powder flowrate $\left(M_{p s}\right)$ & 1.04 & 0.848 & -18.7 \\
Thermal energy requirement $\left(E_{t h \_s}\right)$ & 5900 & 4795 & -18.7 \\
$\quad$ Fluid-bed agglomeration & & & 16.1 \\
$\quad$ Binder flowrate $\left(M_{b}\right)$ & 0.522 & 0.605 & -19.7 \\
Rate of water vaporisation $\left(M_{w f}\right)$ & 0.565 & 0.453 & -19.7 \\
Thermal energy requirement $\left(E_{t h \_}\right)$ & 3697 & 2968 & \\
\hline
\end{tabular}

\subsubsection{Effect of Binder to Powder Ratio on Thermal Energy Analysis}

As highlighted earlier, the mass of binder to powder ratio, or in this analysis, the binder water to powder ratio $\left(R_{w p}\right)$, is an important parameter, which will impact the thermal energy requirements. Consequently, the modelling was applied to evaluate and compare the effect of $R_{w p}$ ratio on the thermal energy requirements of both the spray drying and fluid-bed agglomeration for self-agglomeration (30\% binder solids) and the traditional agglomeration using a water binder. The results are presented in Figure $4 \mathrm{a}$ for $30 \%$ solids concentration in the concentrate. For spray drying, the $R_{w p}$ ratio only influences self-agglomeration because as the $R_{w p}$ ratio increases less concentrate is spray dried, as more of it is required for self-agglomeration in the fluid bed. The net effect is a progressive reduction in spray-dryer thermal energy as the $R_{w p}$ ratio increases for the case of self-agglomeration only.

Figure $4 \mathrm{a}$ also shows that the fluid-bed thermal energy requirement increases for both cases as the $R_{w p}$ ratio increases. This is simply because more binder is being used and more water vaporisation is required. However, the increase is lower for the case of self-agglomeration. As highlighted above, this is because less of the concentrate is spray-dried, resulting in lower powder flowrate to the fluid bed, which in turn, results in lower binder water flowrate $\left(M_{w b}\right)$, which consequentially results in lower fluid-bed thermal energy requirement.

Figure $4 \mathrm{~b}$ shows how the $R_{w p}$ ratio influences total thermal energy (spray drying + fluid bed) for both traditional and self-agglomeration, and the percentage saving in thermal energy for self-agglomeration in comparison to traditional agglomeration. There is a significant increase in total thermal energy for the traditional agglomeration as the $R_{w p}$ ratio increases. This is simply because of the energy required to vaporise the additional water added in the water binder. For self-agglomeration, total thermal energy also increases as the $R_{w p}$ ratio increases but the increase is much lower. This increase is not due to any additional water added because the water vaporised in the fluid bed is from the concentrate as binder and is only off-setting water being vaporised in the spray dryer. The increase is simply because the fluid bed is less energy-efficient than the spray dryer, and total energy increases as more concentrate binder is added, resulting in more of the concentrate being effectively dried in the fluid bed. The rationale provided above results in a progressive increase in percentage saving in thermal energy requirement of self-agglomeration in comparison to traditional agglomeration, as illustrated in Figure $4 b$. 
(a)
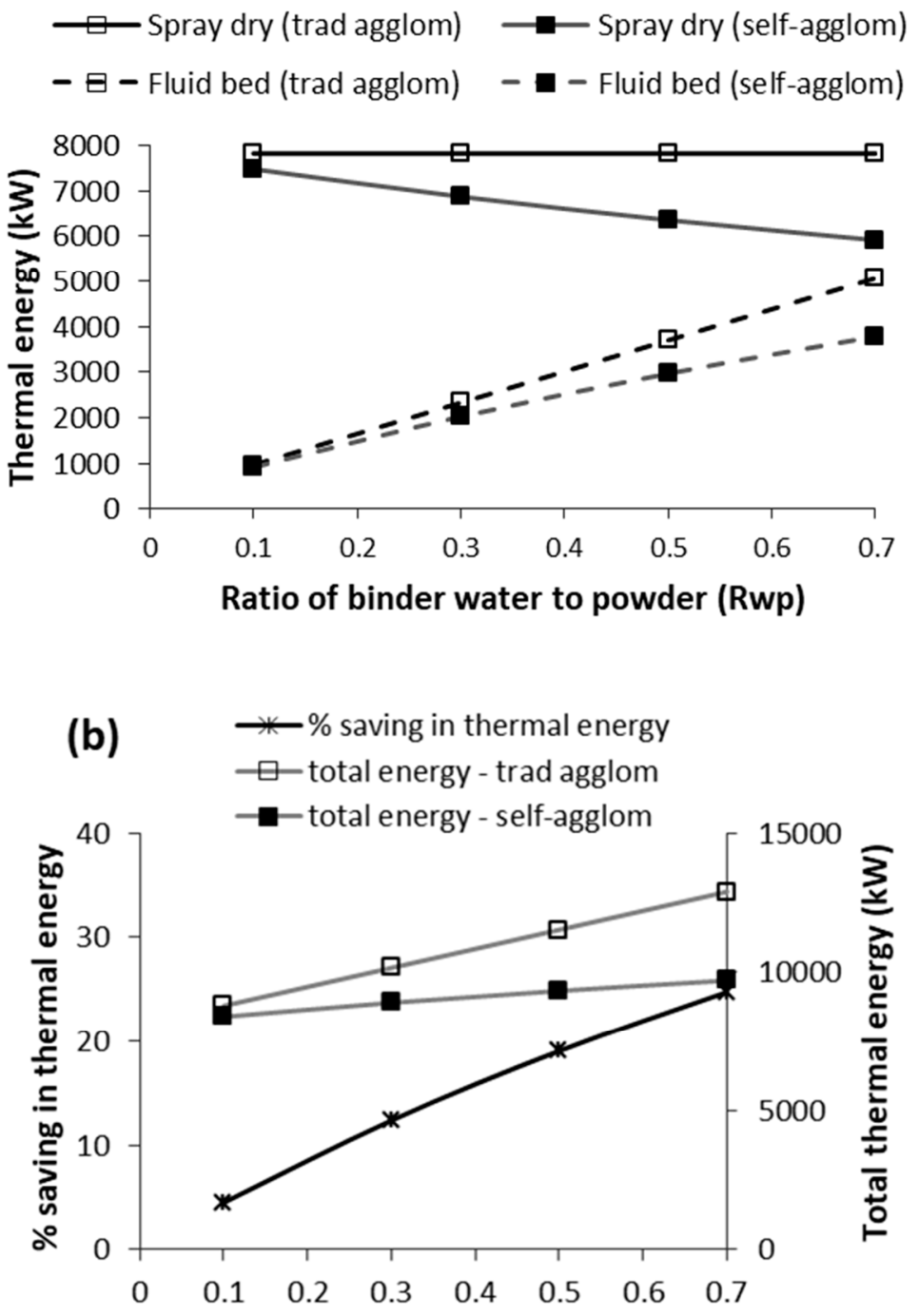

Ratio of binder water to powder (Rwp)

Figure 4. Effect of ratio of binder water to powder $\left(R_{w p}\right)$ on thermal energy requirements of traditional agglomeration and self-agglomeration: (a) spray drying and fluid-bed energy; and (b) total energy and $\%$ saving in energy due to self-agglomeration as compared to traditional agglomeration. $\left[X_{c}=30 \%\right.$; binder solids concentration $\left(X_{b}\right)=30 \%$ for self-agglomeration].

\subsubsection{Effect of Binder Solids Concentration on Thermal Energy Analysis of Self-Agglomeration}

As also highlighted earlier, the binder solids concentration $\left(X_{b}\right)$ in self-agglomeration is an important parameter, which will impact the thermal energy requirements. In fluid-bed agglomeration, it may not be practically feasible to satisfactorily agglomerate at a binder solids concentration equal to that in the concentrate $\left(X_{c}\right)$. Consequently, the modelling was applied to evaluate the effect of $X_{b}$ on the thermal energy requirements of both the spray drying and fluid-bed self-agglomeration for low binder addition $\left(R_{w p}=0.1\right)$ and high binder addition $\left(R_{w p}=0.7\right)$. The results are presented in Figure 5 for $30 \%$ solids concentration in the concentrate. 

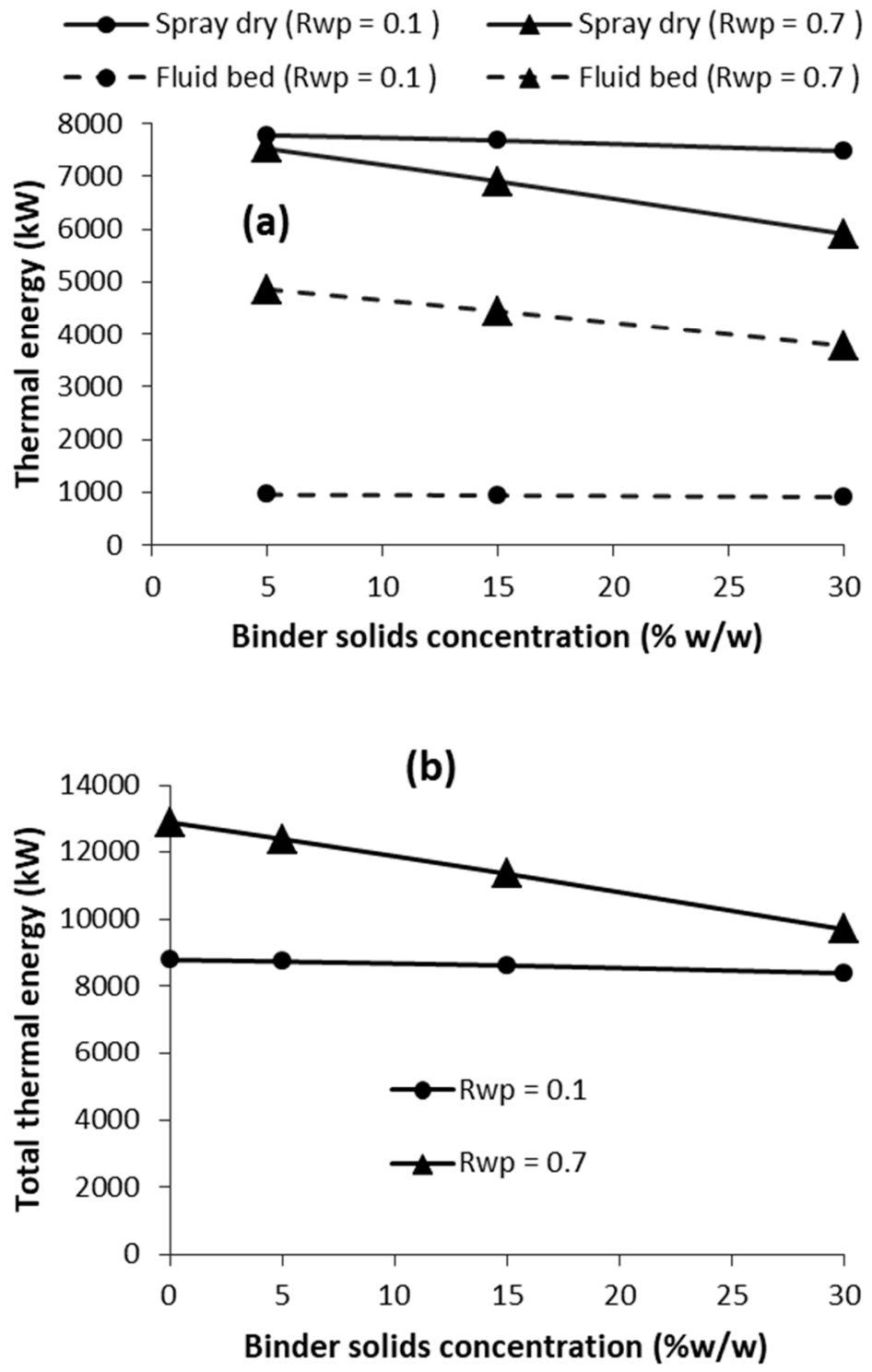

Figure 5. Effect of binder solids concentration $\left(X_{b}\right)$ on thermal energy requirement of self-agglomeration: (a) energy for spray drying and fluid bed, and (b) total energy, at low and high values of $R_{w p}\left[X_{c}=30 \%\right]$.

Looking at the case of high binder addition $\left(R_{w p}=0.7\right.$ in Figure $\left.5 \mathrm{a}\right)$, increasing $X_{b}$ up to $X_{c}$ lowers both the spray dryer and fluid-bed thermal energy requirements, which in turn, lowers total energy (Figure $5 b$ ). The reason for this is that the concentrate is the binder at $X_{b}=X_{c}$, while at $X_{b}<X_{c}$, water needs to be added to the concentrate to dilute it to $X_{b}$. This represents additional water in the binder that needs additional thermal energy supply in the fluid bed to vaporise it. Consequently, the fluid-bed thermal energy requirement decreases as $X_{b}$ increases. Furthermore, more concentrate is added as binder in the fluid bed as $X_{b}$ increases (for a constant $R_{w p}$ ), thus less concentrate is dried in the spray dryer, resulting in a reduction in spray-dryer thermal energy requirement, as $X_{b}$ increases. Overall, the total energy requirement decreases with increasing $X_{b}$, as a result of the decreases in both spray dryer and fluid-bed thermal energy.

For the case of low binder addition $\left(R_{w p}=0.1\right)$, the effect of $X_{b}$ on thermal energy requirement has the same trend as for $R_{w p}=0.7$, except that it is less significant due to the low amount of binder added. As already discussed in Section 3.2.3, Figure 5 also illustrates that higher values of $R_{w p}$ results in lower spray-dryer thermal energy requirement but higher fluid bed and total thermal energy requirements. Considering this and the results presented in this section, it is desirable from a thermal 
energy perspective to operative at as low a $R_{w p}$ value as possible and at a value of $X_{b}$ as close to $X_{c}$ as possible.

\subsubsection{Effect of Concentrate Solids Concentration on Thermal Energy Analysis}

The solids concentration in the concentrate fed to the spray dryer $\left(X_{c}\right)$ will vary from product to product, and represents an upper limit on binder solids concentration $\left(X_{b}\right)$. This will impact on the thermal energy analysis, and is investigated in this section. Figure 6 illustrates the effect of $X_{c}$ on the thermal energy analysis for both traditional wet agglomeration and self-agglomeration $\left(R_{w p}=0.5\right.$; $X_{b}=X_{c}$ for self-agglomeration). As expected, higher $X_{c}$ results in lower thermal energy requirement in the spray dryer (Figure 6a), simply because there is less water to vaporise. The spray-dryer thermal energy requirement is lower for the self-agglomeration because less concentrate is spray dried due to some of the concentrate being used as binder in the fluid bed, as highlighted earlier.
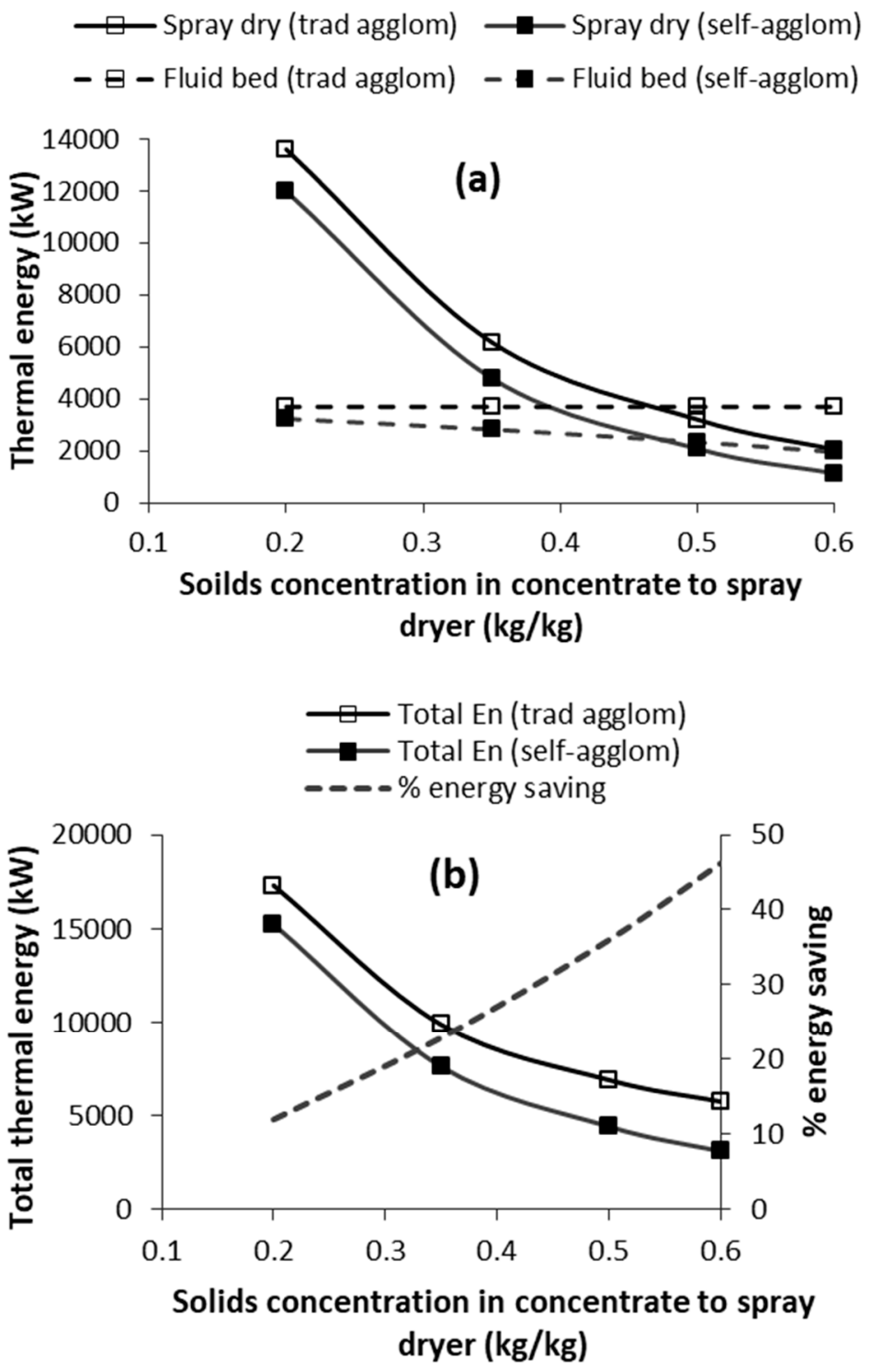

Figure 6. Effect of solids concentration $\left(X_{c}\right)$ in the concentrate to the spray dryer on thermal energy requirements of traditional agglomeration and self-agglomeration: (a) spray drying and fluid-bed energy; and (b) total energy and \% saving in energy due to self-agglomeration as compared to traditional agglomeration. [ $R_{w p}=0.5 ; X_{b}=X_{c}$ for self-agglomeration $]$. 
Figure $6 \mathrm{a}$ also shows the effect of $X_{c}$ on thermal energy requirement of the fluid bed. For traditional agglomeration, the thermal energy requirement is constant irrespective of $X_{c}$ because the amount of powder and binder do not vary with $X_{c}$. For self-agglomeration, the thermal energy requirement of the fluid bed decreases with increase in $X_{c}$. This is because the binder solids concentration equals the solids concentration in the concentrate (i.e., $X_{b}=X_{c}$ in Figure 6), resulting in more concentrate solids being fed as binder to the fluid bed at higher $X_{c}$, and thus less being spray dried. Consequently, there is less spray-dried powder to be agglomerated resulting in less binder water and thus less vaporisation in the fluid bed.

The effect of $X_{c}$ on total thermal energy requirements for both traditional agglomeration and self-agglomeration are shown in Figure 6 b, along with the percentage energy saving associated with self-agglomeration. Total energy reduces for both at higher $X_{c}$ as a result of the data in Figure 6a. The $\%$ energy saving associated with self-agglomeration increases at higher $X_{c}$, where the saving increases from $12 \%$ (at $X_{c}=20 \%$ ) to $46 \%$ (at $X_{c}=60 \%$ ). This is due \% energy saving associated with both spray drying and the fluid bed. Overall, the thermal energy requirement decreases for both agglomerations at higher $X_{c}$; however, the impact is greater for self-agglomeration.

\section{Conclusions}

Self-agglomeration of spray-dried powder in a fluid bed has advantages over traditional fluid-bed wet agglomeration. Binder water to powder ratio $\left(R_{w p}\right)$ and binder solids concentration $\left(X_{b}\right)$ are important parameters, and vary depending on the powder. Laboratory- or pilot-scale testing is required to investigate this, and was undertaken for WPI powder as a case-study. It was shown that satisfactory agglomeration could be achieved with $X_{b}$ values up to at least $30 \%$ (for $R_{w p}=0.5$ ). Binder solids concentration showed some influence on the particle size and bulk densities of the agglomerates, with the $20 \%$ WPI displaying the largest particle size and smallest bulk densities. The self-agglomerated WPI powders displayed a large improvement in powder wettability, in comparison to non-agglomerated WPI, and was similar to that of the powder agglomerated with distilled water.

The thermal energy modelling was implemented to investigate the potential energy advantage associated with self-agglomeration. For the specific case of WPI powder self-agglomeration, the modelling showed that a $19 \%$ reduction in thermal energy was possible in comparison to traditional wet agglomeration. The modelling showed how $R_{w p}, X_{b}$ and $X_{c}$ influence the thermal energy requirement of self-agglomeration and the \% thermal energy saving in comparison to traditional wet agglomeration. For self-agglomeration, it is desirable to use as little binder as possible (i.e., low $R_{w p}$ ) because the spray dryer is more energy-efficient; however, this is limited by the agglomeration ability of the powder. Furthermore, it is desirable to utilise a binder solids concentration equal to the solids concentration in the concentrate to the spray dryer; however, the binder solids concentration may also be constrained by the ability of the powder to agglomerate. A binder solids concentration lower than that in the concentrate will require addition of water, which will reduce the magnitude of the energy-saving advantage of self-agglomeration.

Author Contributions: J.J.F. and S.M. supervised all of the work presented in the paper. J.J.F. conducted the mathematical modelling and wrote the paper. S.W. conducted the experimental work and contributed to writing the experimental part of the paper. All authors contributed to the analysis and interpretation of the results, and review of the paper. All authors have read and agreed to the published version of the manuscript.

Funding: The experimental part of the paper was financially supported by the China Scholarship Council (No.201606350091) and Teagasc (MDDT0153).

Conflicts of Interest: The authors declare no conflict of interest. 


\section{References}

1. Cuq, B.; Mandato, S.; Jeantet, R.; Saleh, K.; Ruiz, T. Food powder agglomeration. In Handbook of Food Powders; Bhandari, B., Bansal, N., Zhang, M., Schuck, P., Eds.; Series in Food Science, Technology and Nutrition; Woodhead Publishing: Cambridge, UK, 2013.

2. Gaiani, C.; Schuck, P.; Scher, J.; Hardy, J.; Desobry, S.; Banon, S. Dairy powder rehydration: Influence of protein state, incorporation mode, and agglomeration. J. Dairy Sci. 2007, 90, 570-581. [CrossRef]

3. Sharma, A.; Jana, A.H.; Chavan, R.S. Functionality of Milk Powders and Milk-Based Powders for End Use Applications-A Review. Compr. Rev. Food Sci. Food Saf. 2012, 11, 518-528. [CrossRef]

4. Turchiuli, C.; Smail, R.; Dumoulin, E. Fluidized bed agglomeration of skim milk powder: Analysis of sampling for the follow-up of agglomerate growth. Powder Technol. 2012, 238, 161-168. [CrossRef]

5. Barkouti, A.; Turchiuli, C.; Carcel, J.A.; Dumoulin, E. Milk powder agglomerate growth and properties in fluidized bed agglomeration. Dairy Sci. Technol. 2013, 93, 523-535. [CrossRef]

6. Ji, J.; Fitzpatrick, J.; Cronin, K.; Maguire, P.; Zhang, H.; Miao, S. Rehydration behaviours of high protein dairy powders: The influence of agglomeration on wettability, dispersibility and solubility. Food Hydrocoll. 2016, 58, 194-203. [CrossRef]

7. Ji, J.; Cronin, K.; Fitzpatrick, J.; Fenelon, M.; Miao, S. Effects of fluid bed agglomeration on the structure modification and reconstitution behaviour of milk protein isolate powders. J. Food Eng. 2015, 167, 175-182. [CrossRef]

8. Ji, J.; Fitzpatrick, J.; Cronin, K.; Fenelon, M.; Miao, S. The effects of fluidized bed and high shear mixer granulation processes on water adsorption and flow properties of milk protein isolate powder. J. Food Eng. 2017, 192, 19-27. [CrossRef]

9. Tetra Pak. Milk and whey powder. In Dairy Processing Handbook, 3rd ed.; Tetra Pak International SA: Lund, Sweden, 2015.

10. Chever, S.; Mejean, S.; Dolivet, A.; Mei, F.; Den Boer, C.M.; Le Barzic, G.; Jeantet, R.; Schuck, P. Agglomeration during spray drying: Physical and rehydration properties of whole milk/sugar mixture powders. LWT-Food Sci. Technol. 2017, 83, 33-41. [CrossRef]

11. Tetra Pak. Whey processing. In Dairy Processing Handbook, 3rd ed.; Tetra Pak International SA: Lund, Sweden, 2015.

12. Kemp, I. Fundamentals of Energy Analysis of Dryers. In Modern Drying Technology, Volume 4: Energy Savings; Tsotsas, E., Mujumdar, A.J., Eds.; Wiley-VCH: Weinheim, Germany, 2012.

13. Moejes, S.N.; Visser, Q.; Bitter, J.H.; van Boxtel, A.J.B. Closed-loop spray drying solutions for energy efficient powder production. Innov. Food Sci. Emerg. Technol. 2018, 47, 24-37. [CrossRef]

14. Patel, S.K.; Bade, M.H. Energy analysis and heat recovery opportunities in spray dryers applied for effluent management. Energy Convers. Manag. 2019, 186, 597-609. [CrossRef]

15. Domínguez-Niño, A.; Cantú-Lozano, D.; Ragazzo-Sanchez, J.A.; Andrade-González, I.; Luna-Solano, G. Energy requirements and production cost of the spray drying process of cheese whey. Dry. Technol. 2018, 36, 597-608. [CrossRef]

16. Baker, C.G.J.; McKenzie, K.A. Energy Consumption of Industrial Spray Dryers. Dry. Technol. 2005, 23, 365-386. [CrossRef]

(C) 2020 by the authors. Licensee MDPI, Basel, Switzerland. This article is an open access article distributed under the terms and conditions of the Creative Commons Attribution (CC BY) license (http://creativecommons.org/licenses/by/4.0/). 